\title{
Cervical cancer, its screening and vaccination: a KAP study among female healthcare students in a Private University, Malaysia
}

\begin{abstract}
Introduction: Cervical Cancer (CC), the entirely preventable cancer is the second largest killer in low and middle-income countries, with most death in women's prime of life. The objective was to assess the knowledge, attitude \& perception (KAP) related to cervical cancer, its screening and vaccination among female University students from medical, dental and pharmacy (healthcare) background.
\end{abstract}

Method: A cross sectional study among 507 female undergraduate students using convenience sampling. The data were analysed using SPSS version 23. Descriptive analysis for frequency and percentage was performed and Spearman's correlations run for inferential statistics.

Results: In this study, the majority had ever heard of CC; $94 \%$ knew, it only infects females; $57 \%$ aware CC is symptomless; $83 \%$ believed, it is curable; $72 \% \mathrm{knew}$, it is detected by Pap test; $80 \%$ knew, it is caused by HPV; $57 \%$ knew the HPV types and $91 \%$ knew vaccination reduces risk. Majority had poor (55\%) knowledge, neutral $(67 \%)$ attitude \& perception and moderate $(72 \%)$, total KAP score towards CC and its study domains.

Conclusion: Majority of the students had poor knowledge score, optimum attitude $\&$ perception towards $\mathrm{CC}$ related domains. Providing clear, precise and tailored information about implications of $\mathrm{CC}$, its screening and vaccination is of importance.

Keywords: cervical cancer, screening, vaccination, knowledge, attitude and perception, students, disease, health, medical, pharmacy
Volume 5 Issue 5 - 2018

\author{
Abdul Nazer Ali,' Lee Kar Mun,' Sunil Kumar \\ Prajapati,' Muhammad Zahid lqbal,' Nazer \\ Zulfikar Ahmed ${ }^{2}$ \\ 'Faculty of pharmacy, AIMST University, Malaysia \\ ${ }^{2}$ Cognizant Technology Solutions India Private Limited, India
}

\author{
Correspondence: Abdul Nazer Ali, Faculty of Pharmacy, \\ AIMST University, Semeling, 08I 00 Bedong, Kedah Darul Aman, \\ Malaysia,Tel +60 I0 373 0262, Email \\ abdul.nazerala16@gmail.com
}

Received: September II, 2018 | Published: October 24, 2018

\section{Introduction}

Cervical cancer (CC) is a malignant tumour of the cervix affecting the outermost squamous or inner glandular cells. ${ }^{1}$ Mostly, cervical cancer progresses slowly (10-15 years) and often symptomless until advanced. It is the fourth most common cancer in women, worldwide. ${ }^{2}$

HPV infection has been implicated as the primary agent, diagnosed through routine screening based on clinical history and/ or physical findings (cytology), and confirmed by cervical punch or cone biopsy. ${ }^{1-2}$ Prognosis varies based on disease stage, with $92 \%$, 5 -year survival rates (localized disease) and $16.8 \%$ for metastasised (distant) disease. ${ }^{3}$

A study in US reported CC is killing women at a much higher rate than previously estimated. ${ }^{4}$ A large majority (85\%) of the global burden occurs in less developed regions, with estimated age-standardized rates over 30/100,000 which includes: Eastern Africa (42.7), Melanesia (33.3), Southern (31.5) and Middle (30.6) Africa. Rates are lowest in Australia/New Zealand (5.5) and Western Asia (4.4). Because of the lack of cancer registries, it is likely that reported incidence and mortality rates, may grossly underestimate the magnitude of the problem. ${ }^{5}$ The relatively high international mortality rates are due to presentation at advanced stage, limited screening, and non-existent access to medical resources and/or inadequate patient education. ${ }^{6}$

This entirely preventable disease is the second largest cancer killer of women in low and middle-income countries, with most women dying in their prime of life. The Ministry of Health, Malaysia reported an average 2000 to 3000 hospital admissions of CC cases per year, most of them (between 15 and 44 years) presenting late into the disease and $88.7 \%$ are attributed to HPV type 16 or $18 .{ }^{7,8}$ Low level of awareness, lack of effective screening programs, overshadowed by other health priorities (AIDS, TB, malaria) and insufficient attention to women's health are the possible factors for the observed higher incidence rate of cervical cancer in Malaysia. ${ }^{7,8}$ Projections show that by 2030 , almost half a million women will die of cervical cancer, with over $98 \%$ expected to occur in low and middle-income countries if not HPV vaccinated. ${ }^{9}$

There are compelling evidence for a causal relationship between CC and HPV (types 16 and 18) and HPV vaccination is effective in reduced incidence of moderate and severe cervical intra-epithelial neoplasia (CIN) in patients without prior infection. ${ }^{10}$ Early pre-cancer screening (colposcopy), visual inspection with acetic acid and HPV testing can help diagnose the early cancer. Most study findings confer, creating awareness of $\mathrm{CC}$ and knowledge of screening improve screening practice. Hence, this study intended to assess the awareness, knowledge, attitude and perception among young university female students on cervical cancer, its screening and vaccination. The study outcome will hopefully provide useful information for appropriate interventions needed in order to deter suffering and death linked with $\mathrm{CC}$.

\section{Outcome measures}

To assess the level of knowledge, attitude/perception and total KAP related to cervical cancer, its screening and vaccination among female University students from medical, dental and pharmacy graduate 
courses in a private university, Kedah state, Malaysia. To find out the association and correlation between knowledge, attitude/perception and total KAP scores related to cervical cancer, its screening and vaccination among the study participants.

\section{Methods and materials}

This was a questionnaire based, cross-sectional study using convenience sampling technique, conducted between March to May, 2018. Female under-graduate students, aged 18 years and above belonging to medical, dental and pharmacy courses of a private university, Kedah state, Malaysia were included and those who participated in the pilot study; did not give consent; male and/or incomplete survey forms were excluded from the study. The sample size was calculated using automated on-line software (Raosoft sample size calculator). The estimated sample size was calculated at 95\% CI, $5 \%$ margin of error and 50\% response distribution. The estimated sample size based on female students' admission registry for the three schools was 302 ; the recommended sample (plus 20\%) was rounded off to 360 in order to overcome any errors and increase the reliability of results.

\section{Development of the questionnaire}

The questions for the survey were mostly adapted from other published articles, designed to test the domains of the study participants (Knowledge, Attitude and Perception) and collect the following information: socio-demographic details like age, gender, etc.; questions to assess knowledge; statements/questions to assess attitude and perception; sources of information regarding $\mathrm{CC}$, its screening and vaccination. ${ }^{11}$ The initial study questionnaire contained socio-demographic data, 20 knowledge testing items and 12 attitude/ perception based items

\section{Validation of the questionnaire}

The adapted 32 item questionnaire was content validated for its appropriateness to meet the study objectives by a group of six experts from clinical pharmacy and pharmacy practice unit, faculty of pharmacy, AIMST University, Malaysia. This questionnaire was later scrutinized by a couple of experts from Community Medicine and Gynaecology/Obstetrics, faculty of medicine. One knowledge based question was removed as found inappropriate. After content validation was satisfactory, face validation was done among 30 potential respondents (10 from each school). The participants were encouraged to inquire any doubt or confusion regarding the items and explained for better understanding and noted for subsequent adjustment by the researcher. The 31 item KAP questionnaire was thus arrived. The reliability test for internal consistency was conducted among 30 participants using Cronbach's alpha test. The alpha value was found to be .65 for the initial 31 items. Two knowledge item and two attitude/ perception items were removed due to negative correlations. Hence, the final 27 item KAP questionnaire $(17$ knowledge and 10 attitude \& perception items) showed an acceptable reliability of $\alpha=.725$ and was used for the study.

\section{Modality of obtaining response}

The study participants were verbally explained about the study objectives and informed consent forms were signed before distribution of survey forms. The completed questionnaires (average time taken $=15-20$ minutes) were retrieved and compiled for data analysis.

\section{Scoring grades and pattern}

The scoring grades attributed to each domain and overall, were adopted from the Original Bloom's cut off points, score of $80-100 \%$ correct response as good, $60-79 \%$ as satisfactory and score $<60 \%$ as poor knowledge. ${ }^{12}$

\section{Ethical considerations}

The research proposal along with the study instruments and informed consent form was submitted to the Institutional Review Board (AIMST University Human Ethical Committee) and the ethical clearance was obtained before initiating the study.

\section{Statistical analyses of data}

The analysis was performed using IBM SPSS Statistics for Windows (Version 23. Armonk, NY: IBM Corp.). Descriptive statistics for frequency and percentage was computed for categorical variables. Numerical data (distribution not normal) was presented as median and interquartile range. The Chi-square test for independence was used for association between variables and $\mathrm{p}<.05$ was considered statistically significant. The inferential statistics was done using Spearman's rank correlation. The significance level was set at .05 for all statistical tests. All percentage displayed in the text or in parentheses are with no decimal places (Figure 1a-1c).

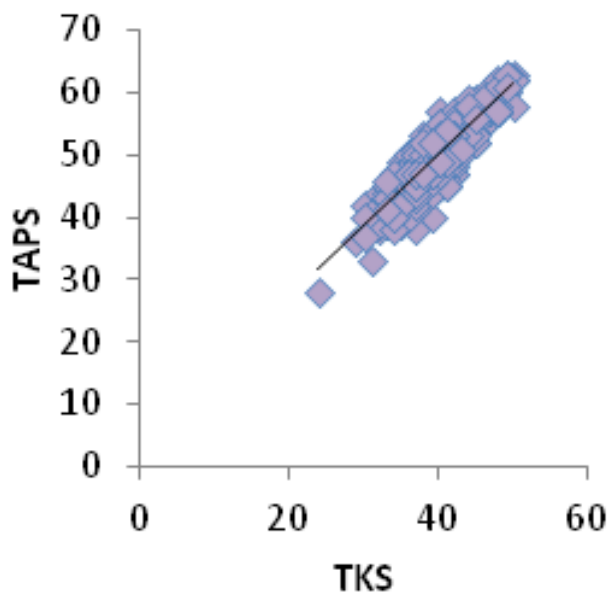

Figure I A Monotonically increasing [TKS and TAPS].

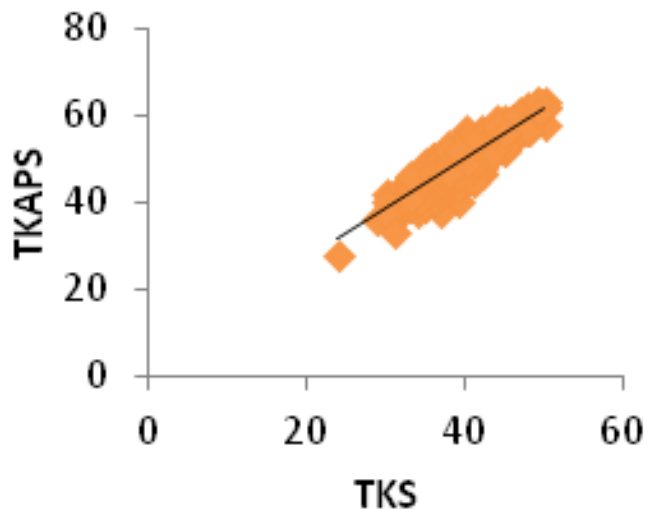

Figure I B Monotonically increasing [TKS vs TKAPS]. 


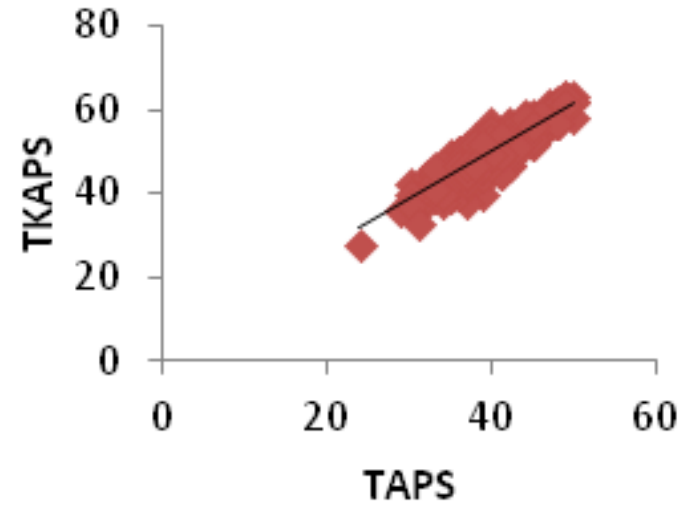

Figure IC Monotonically increasing [TAPS vs TKAPS].

Figure I Spearman's rank order correlation between outcome measures.

**Correlation is significant at the 0.0 I level (2-tailed). TKS; total knowledge score, TAPS; total attitude/perception score, TKAPS; total knowledge attitude and perception score.

\section{Results}

Among the 700 questionnaires distributed, 507 (72\%) valid questionnaires were retrieved with $28 \%$ drop-outs due to incomplete questionnaire or unwilling to participate.

\section{Socio-demographic characteristics}

Among the 507 female adult participants, most of them were: aged 21-23 years, Chinese; pharmacy students;

year three study; unmarried and from urban location. The sociodemographic information is presented in Table 1.

Table 1 Socio-demographic characteristics

\begin{tabular}{ll}
\hline Variables $(\mathbf{N}=\mathbf{5 0 7})$ & $\mathbf{N}(\mathbf{\%})$ \\
\hline Age in years & \\
$18-20$ & $105(21)$ \\
$21-23$ & $378(75)$ \\
$24-26$ & $21(4)$ \\
$>26$ & $3(1)$ \\
Race & \\
Malay & $6(1)$ \\
Indian & $84(17)$ \\
Chinese & $417(82)$ \\
Course of studying & \\
Pharmacy & $219(43)$ \\
Dental & $139(27)$ \\
Medicine & $149(29)$ \\
Year of study & $129(24)$ \\
Year 1 & $90(18)$ \\
Year 2 & \\
Year 3 & \\
Year 4 & \\
\hline
\end{tabular}

\begin{tabular}{ll}
\hline Variables $(\mathbf{N}=\mathbf{5 0 7})$ & $\mathbf{N}(\mathbf{\%})$ \\
\hline Relationship status & $1(0.2)$ \\
Married & $89(18)$ \\
In relationship & $417(82)$ \\
Single & \\
Are you a smoker & $7(1)$ \\
Yes & $500(99)$ \\
No & \\
Native Location & $389(77)$ \\
Urban & $118(23)$ \\
Rural &
\end{tabular}

Frequency and percentages distribution.

\section{Knowledge about cervical cancer, its screening and} vaccination

The proportion of correct responses to 17 knowledge items regarding cervical cancer, its screening and vaccination is summarized in Table 2. Each correct response was assigned one mark and sum of all items represent the total knowledge score ('0' to ' 17 ').

Most of the participants had an overall poor knowledge score (59\%) about cervical cancer, its screening and vaccination. Mostly all were aware of CC (97\%); it affects only females $(94 \%)$; risk can be reduced by HPV vaccination (91\%); is curable if detected early ( $83 \%)$ and HPV is the main cause for CC (80\%). The least awareness was reported for, $\mathrm{CC}$ is more common in women $<30$ years $(34 \%)$; takes long time to progress into cancer (34\%); weather CC is curable (17\%) and the rate at which it grows (16\%).

\section{Attitude and perception about cervical cancer, its screening and vaccination}

The responses towards the ten attitude \& perception based items is summarized in Table 3. A five point Likert scale from strongly disagree (1 point) to strongly agree ( 5 points) was assigned for negative to positive responses and the sum of scores (10 to 50) represent the total attitude/perception score.

An overall, neutral attitude/perception was observed in this study. The highest positive attitude/perception response was received for: free screening program (95\%); vaccination prevents CC (93\%); consult a doctor if abnormal vaginal bleeding (85\%); willing for regular screening (82\%); regular screening helps early detection $(79 \%)$ and multiple sex partners are high risk for CC $(73 \%)$ respectively, whereas the negative attitude/ perception responses were recorded for: condom use reduce cancer risk (49\%) and long term use of contraceptive pills $(55 \%)$.

\section{The overall knowledge, attitude/perception and KAP scores}

Among the 507 participants, 149 were from medical, 139 from dental and 219 from pharmacy. An overall poor knowledge score was reported among the three study groups. There was no significant differences, $\mathrm{X}^{2}(4, \mathrm{~N}=507)=9.07 ; p=.059$, between total knowledge score (TKS) and course of study (Table 4). Medical students had a slightly higher median knowledge score, 11(3) towards knowledge. An overall neutral attitude/perception was reported among the study populations. There was a significant difference between total attitude/ 
perception score (TAPS), $\mathrm{X}^{2}(4, \mathrm{~N}=507)=12.59 ; p=.013$ and course of study. The dental students showed better median attitude/perception score 40 (4). The overall KAP score reported was neutral and no significant difference were observed, $\mathrm{X}^{2}(4, \mathrm{~N}=507)=.73 ; p=.201$ between total KAP score (TKAPS) and course of study. Medical and dental students had a slightly higher median KAP scores, 50(7) and 50(6) respectively.

Table 2 Responses to knowledge based items $(\mathrm{N}=507)$

\begin{tabular}{|c|c|c|c|c|}
\hline Qn.No. & Knowledge items & Correct N (\%) & Incorrect $\mathbf{N}(\%)$ & *p value \\
\hline 1 & Have you ever heard about cervical cancer? & $494(97)$ & $13(3)$ & $<.001$ \\
\hline 2 & Cervical cancer infects only females. & $475(94)$ & $32(6)$ & $<.001$ \\
\hline 3 & Cervical cancer at early stage produces no signs or symptoms. & $287(57)$ & $220(43)$ & 0.003 \\
\hline 4 & Is cervical cancer curable? & $86(17)$ & $421(83)$ & $<.001$ \\
\hline 5 & Cervical cancer is a fast growing cancer? & $82(16)$ & $425(84)$ & $<.001$ \\
\hline 6 & If detected early, is cervical cancer curable? & $422(83)$ & $85(17)$ & $<.001$ \\
\hline 7 & Cervical cancer risk can be reduced by HPV vaccination. & $459(91)$ & $48(10)$ & $<.001$ \\
\hline 8 & Cervical cancer is more common in women younger than 30 years. & $174(34)$ & $333(66)$ & $<.001$ \\
\hline 9 & Getting a Pap test helps early detection of cervical cancer. & $363(72)$ & $144(28)$ & $<.001$ \\
\hline 10 & Smoking is one of the potential complications for cervical cancer. & $218(43)$ & $289(57)$ & 0.002 \\
\hline 11 & Human papillomavirus (HPV) is the main cause of cervical cancer. & $404(80)$ & $103(20)$ & $<.001$ \\
\hline 12 & $\mathrm{HPV}$ is very common in women younger than 30 years. & $188(37)$ & $319(63)$ & $<.001$ \\
\hline 13 & HPV vaccination is available for girls aged 9 to 26 years. & $367(72)$ & $140(28)$ & $<.001$ \\
\hline 14 & What are the symptoms of cervical cancer? & $315(62)$ & $192(38)$ & $<.001$ \\
\hline 15 & How long does it take for the abnormal cervical cells to turn into cancerous cells? & $170(34)$ & $337(67)$ & $<.001$ \\
\hline 16 & $70 \%$ of cervical cancer is caused by HPV types 16 and 18. & $288(57)$ & $219(43)$ & 0.002 \\
\hline 17 & What is the common and effective treatment to cure cervical cancer? & $325(64)$ & $182(36)$ & $<.001$ \\
\hline
\end{tabular}

*Chi square test ( $\mathrm{p}<.05$ is considered statistically significant).

Table 3 Responses for attitude and perception based items $(\mathrm{N}=507)$

\begin{tabular}{|c|c|c|c|c|c|c|}
\hline Q.No. & Attitude and perception statements & SD N(\%) & D N(\%) & NS N(\%) & $A N(\%)$ & SA N(\%) \\
\hline 1 & $\begin{array}{l}\text { Are you willing to regularly consult a medical doctor for cervical cancer } \\
\text { screening? }\end{array}$ & $2(0.4)$ & $15(3)$ & $75(15)$ & $292(58)$ & $123(24)$ \\
\hline 2 & Those with multiple sex partners will be at higher risk for cervical cancer. & $0(0)$ & $11(2)$ & $126(25)$ & 241(48) & $129(25)$ \\
\hline 3 & Long term use of contraceptive pills could cause cervical cancer. & $2(0.4)$ & 14(3) & $216(43)$ & $232(46)$ & $43(9)$ \\
\hline 4 & The use of condoms could reduce the risk of cervical cancer. & $2(0.4)$ & $36(7)$ & $221(44)$ & 213(42) & $35(7)$ \\
\hline 5 & HPV vaccination can prevent cervical cancers. & $0(0)$ & $7(1)$ & $28(6)$ & 289(57) & $183(36)$ \\
\hline 6 & $\begin{array}{l}\text { Will you consult a medical doctor in case of abnormal bleeding between } \\
\text { menstrual periods? }\end{array}$ & $2(0.4)$ & $15(3)$ & $56(11)$ & 286(56) & $148(29)$ \\
\hline 7 & Regular Pap smear test helps an early detection of cervical cancer. & $0(0)$ & $5(17)$ & 107(21) & 271(54) & $124(25)$ \\
\hline 8 & Are you willing to get a Pap smear test? & $0(0)$ & $17(3)$ & $119(24)$ & $260(51)$ & $111(22)$ \\
\hline 9 & Are you willing to pay for a Pap smear test? & $3(1)$ & $34(7)$ & $153(30)$ & $226(45)$ & $91(18)$ \\
\hline 10 & $\begin{array}{l}\text { Government should provide free screening program to reduce cervical } \\
\text { cancer prevalence. }\end{array}$ & $0(0)$ & $6(1)$ & $17(3)$ & 198(39) & $286(56)$ \\
\hline
\end{tabular}

$\mathrm{SD}$, strongly disagree; $\mathrm{D}$, disagree; $\mathrm{N}$, not sure; A, agree; SA, strongly agree

Distribution of overall KAP scores about cervical cancer, its screening and vaccination

An overall total KAP scores observed was $72 \%$ and $63 \%$, both moderate for cervical cancer infection $\left[\mathrm{X}^{2}(2, \mathrm{~N}=507)=241.56\right.$; $\mathrm{p}<.001]$ and cervical cancer screening $\left[\mathrm{X}^{2}(2, \mathrm{~N}=507)=196.73\right.$; $\mathrm{p}<.001]$ respectively and $65 \%$ good for cervical cancer vaccination $\left[\mathrm{X}^{2}(2, \mathrm{~N}=507)=354.76 ; p<.001\right]$ (Table 5). 
Table 4 Distribution of median and percentage scores among healthcare students

\begin{tabular}{|c|c|c|c|c|c|c|}
\hline Study domains & $\mathbf{N}$ & Median (IQR) & Poor/Negative N (\%) & Moderate/Neutral N(\%) & Good/Positive N(\%) & p value \\
\hline \multicolumn{7}{|c|}{ Total knowledge score (TKS) } \\
\hline Medicine & 149 & 11(3) & $70(47)$ & $69(46)$ & $10(7)$ & \multirow[t]{3}{*}{0.059} \\
\hline Dental & 139 & $10(3)$ & $82(59)$ & $47(34)$ & $10(7)$ & \\
\hline Pharmacy & 219 & $10(3)$ & 129(59) & $83(38)$ & $7(3)$ & \\
\hline \multicolumn{7}{|c|}{ Total attitude \& perception score (TAPS) } \\
\hline Medicine & 149 & $39(6)$ & $16(11)$ & $88(59)$ & $45(30)$ & \multirow[t]{3}{*}{$.013 *$} \\
\hline Dental & 139 & $40(4)$ & $3(2)$ & 102(73) & $34(25)$ & \\
\hline Pharmacy & 219 & $39(5)$ & $11(5)$ & $148(68)$ & $60(27)$ & \\
\hline \multicolumn{7}{|c|}{ Total knowledge, attitude \& perception score (TKAPS) } \\
\hline Medicine & 149 & $50(7)$ & $30(20)$ & $99(66)$ & $20(13)$ & \multirow[t]{2}{*}{0.201} \\
\hline Pharmacy & 219 & $49(6)$ & 29(13) & $158(72)$ & $32(15)$ & \\
\hline
\end{tabular}

*Chi square test $(\mathrm{p}<.05$ is considered statistically significant).

Table 5 Overall total KAP score regarding cervical cancer infection, its screening and vaccination status among study participants

\begin{tabular}{lll}
\hline Variables & N (\%) & p value \\
\hline KAP of cervical cancer $(\mathbf{N = 5 0 7 )}$ & & \\
Poor & $100(20)$ & \\
Moderate & $366(72)$ & $<.001^{*}$ \\
Good & $41(8)$ &
\end{tabular}

KAP of cervical cancer screening $(\mathrm{N}=507)$

$\begin{array}{ll}\text { Poor } & 81(16) \\ \text { Moderate } & 317(63)<<.001 * \\ \text { Good } & 109(22)\end{array}$

KAP of cervical cancer vaccination $(\mathrm{N}=\mathbf{5 0 7})$

Poor

Moderate

$115(23)<.001 *$

Good

HPV vaccination status $(\mathrm{N}=\mathbf{5 0 7})$

$\begin{array}{lll}\text { Vaccinated } & 400(79) \quad<.001 * \\ \text { Not Vaccinated } & 107(21) & \\ \text { No of dosed taken }(\mathbf{N}=\mathbf{4 0 0}) & \\ \text { One dose } & 41(10) \\ \text { Two doses } & 19(5) & <.001^{*} \\ \text { Three doses } & 340(85) \\ \text { Place of HPV vaccination }(\mathbf{N}=\mathbf{4 0 0}) & \\ \text { National immunization at School } & 164(41) \\ \text { LPPKN Clinics } & 174(44) \\ \text { Hospital/Private clinics } & 62(16)\end{array}$

\begin{tabular}{lcc}
\hline Variables & N $(\%)$ & p value \\
\hline Sources of information for screening and vaccination $(\mathbf{N}=\mathbf{4 0 0})$ \\
Newspaper/TV/Internet & $206(52)$ & \\
Medical practitioner & $71(18)$ & $<.001^{*}$ \\
Family/Friends & $123(31)$ & \\
\hline
\end{tabular}

*Chi square test $(\mathrm{p}<.05$ is considered statistically significant).

Regarding the vaccination status, 400/507, 79\% of the participants were HPV vaccinated. Among the vaccinated, mostly 340/400, 85\% have completed all three doses, 174/400, 44\% were vaccinated at National Population and Family Board (LPPKN) Clinics and the main source of information was mass media among 52\%, 206/400. The Chi-square test revealed significant association among all attributes in the study.

Relationship between the study domains and sociodemographic variables among the study population

The KAP score of study domains (CC infection, CC Screening and CC Vaccination) were cross-tabulated with the socio-demographic variables and are summarized in Table 6. Regarding KAP scores of $\mathrm{CC}$ infection, it was observed that only the race and year of study showed statistically significant association $(\mathrm{p}<.01)$. Whereas for $\mathrm{CC}$ screening, age, race, year of study and location showed statistically significant association $(\mathrm{p}<.01)$ and surprisingly, only age category $(\mathrm{p}<.01)$ showed statistically significant association with KAP score regarding $\mathrm{CC}$ vaccination.

Regarding the vaccination status, $400 / 507,79 \%$ of the participants were HPV vaccinated. Among the vaccinated, mostly 340/400, 85\% have completed all three doses, 174/400, 44\% were vaccinated at National Population and Family Board (LPPKN) Clinics and the main source of information was mass media among 52\%, 206/400. The Chi-square test revealed significant association among all attributes in the study. 
Relationship between the study domains and sociodemographic variables among the study population

The KAP score of study domains (CC infection, CC Screening and $\mathrm{CC}$ Vaccination) were cross-tabulated with the socio-demographic variables and are summarized in Table 6 .
Regarding KAP scores of CC infection, it was observed that only the race and year of study showed statistically significant association $(\mathrm{p}<.01)$. Whereas for CC screening, age, race, year of study and location showed statistically significant association $(p<.01)$ and surprisingly, only age category $(\mathrm{p}<.01)$ showed statistically significant association with KAP score regarding $\mathrm{CC}$ vaccination.

Table 6 Participants KAP score distribution regarding cervical cancer Infection, screening \& vaccination

\begin{tabular}{|c|c|c|c|c|c|c|c|c|c|c|c|c|c|}
\hline \multicolumn{3}{|c|}{ Demographic variables } & \multicolumn{4}{|l|}{$\begin{array}{l}\text { CC } \\
\text { infection }\end{array}$} & \multicolumn{4}{|c|}{ CC screening } & \multicolumn{3}{|c|}{$\mathrm{CC}$ vaccination } \\
\hline & $\mathrm{N}(\%)$ & $\mathrm{P}$ & M & G & $\mathrm{p}$ value & $\mathrm{P}$ & $\mathrm{M}$ & G & $\mathrm{p}$ value & $\mathrm{P}$ & $\mathrm{M}$ & G & $\mathrm{p}$ value \\
\hline \multicolumn{14}{|l|}{ Age in years } \\
\hline $18-20$ & $105(21)$ & $25(24)$ & $69(66)$ & 11(11) & 0.286 & $15(14)$ & $54(51)$ & $36(34)$ & $<.001 *$ & $15(14)$ & $17(16)$ & $73(70)$ & $.012 *$ \\
\hline $21-23$ & $378(75)$ & 71(19) & $281(74)$ & $26(7)$ & & $58(15)$ & $253(67)$ & $67(18)$ & & $42(11)$ & $87(23)$ & $249(66)$ & \\
\hline $24-26$ & $21(4)$ & $4(19)$ & $14(67)$ & $3(14)$ & & $8(38)$ & $7(33)$ & $6(29)$ & & $3(14)$ & $11(52)$ & $7(33)$ & \\
\hline$>26$ & $3(1)$ & $0(0)$ & $2(67)$ & $1(33)$ & & $0(0)$ & $3(100)$ & $0(0)$ & & $1(33)$ & $0(0)$ & $2(67)$ & \\
\hline \multicolumn{14}{|l|}{ Race } \\
\hline Malay & $6(1)$ & $1(17)$ & $1(17)$ & $4(67)$ & $<.001^{*}$ & $0(0)$ & $0(0)$ & $6(100)$ & $<.001 *$ & $0(0)$ & $1(17)$ & $5(83)$ & 0.699 \\
\hline Indian & $84(17)$ & $15(18)$ & $61(73)$ & $8(10)$ & & $12(14)$ & $54(64)$ & $85(20)$ & & $13(16)$ & $19(23)$ & $52(62)$ & \\
\hline Chinese & $417(82)$ & $84(20)$ & $304(73)$ & $29(7)$ & & $69(81)$ & $263(63)$ & $109(22)$ & & $48(12)$ & $95(23)$ & $274(66)$ & \\
\hline \multicolumn{14}{|c|}{ Course of studying } \\
\hline Pharmacy & $219(43)$ & $46(21)$ & $157(72)$ & $16(7)$ & 0.948 & $36(16)$ & $134(61)$ & $49(22)$ & 0.605 & $25(11)$ & $56(26)$ & $138(63)$ & 0.296 \\
\hline Dental & $139(27)$ & $25(18)$ & $102(73)$ & $12(9)$ & & $17(12)$ & $93(67)$ & $29(21)$ & & $13(9)$ & $27(19)$ & $99(71)$ & \\
\hline Medicine & 149(29) & $29(20)$ & $107(72)$ & $13(9)$ & & 28(19) & $90(60)$ & $31(21)$ & & $23(15)$ & $32(22)$ & $94(63)$ & \\
\hline \multicolumn{14}{|c|}{ Year of study } \\
\hline Year 1 & $129(25)$ & $32(25)$ & $80(62)$ & $17(13)$ & $.002 *$ & $17(13)$ & $74(57)$ & $38(30)$ & $.006^{*}$ & $16(12)$ & $24(19)$ & $89(69)$ & 0.328 \\
\hline Year 2 & $122(24)$ & $32(26)$ & $84(69)$ & $6(5)$ & & $28(23)$ & $75(62)$ & $19(16)$ & & $20(16)$ & $28(23)$ & $74(61)$ & \\
\hline Year 3 & $166(33)$ & 21(13) & $130(78)$ & $15(9)$ & & $30(18)$ & $102(61)$ & $34(21)$ & & $13(8)$ & $43(26)$ & $110(66)$ & \\
\hline Year 4 & $90(18)$ & $15(17)$ & $72(80)$ & $3(3)$ & & $6(7)$ & $66(73)$ & $18(20)$ & & $12(13)$ & $20(22)$ & $68(64)$ & \\
\hline \multicolumn{14}{|c|}{ Relationship status } \\
\hline Married & $1(0.2)$ & $0(0)$ & $1(100)$ & $0(0)$ & 0.34 & $0(0)$ & $0(0)$ & $1(100)$ & 0.347 & $0(0)$ & $0(0)$ & $1(100)$ & 0.961 \\
\hline $\begin{array}{l}\text { In } \\
\text { relationship }\end{array}$ & $89(18)$ & $12(14)$ & $72(8)$ & $5(6)$ & & 14(16) & $59(66)$ & $16(18)$ & & $10(11)$ & $20(23)$ & $59(66)$ & \\
\hline Single & $417(82)$ & $88(21)$ & $293(70)$ & $36(9)$ & & $67(16)$ & $258(62)$ & $92(22)$ & & $51(2)$ & $95(23)$ & $271(65)$ & \\
\hline \multicolumn{14}{|l|}{ Smoker } \\
\hline Yes & $7(1)$ & $1(14)$ & $6(86)$ & $0(0)$ & 0.65 & $1(14)$ & $5(71)$ & $1(14)$ & 0.872 & $1(14)$ & $3(43)$ & $3(43)$ & 0.396 \\
\hline No & $500(99)$ & $99(20)$ & $360(72)$ & $41(8)$ & & $80(16)$ & $312(62)$ & $108(22)$ & & $60(12)$ & $112(22)$ & $328(66)$ & \\
\hline \multicolumn{14}{|c|}{ Native location } \\
\hline Urban & $389(77)$ & $74(19)$ & $283(73)$ & $32(8)$ & 0.768 & $60(15)$ & $256(66)$ & 73(19) & $.011 *$ & $49(13)$ & $88(23)$ & $252(65)$ & 0.775 \\
\hline Rural & $118(23)$ & $26(22)$ & $83(70)$ & $9(8)$ & & $21(18)$ & $61(52)$ & $36(31)$ & & $12(10)$ & $27(23)$ & $79(67)$ & \\
\hline
\end{tabular}

G, good; M, moderate; P, poor; CC, cervical cancer; ${ }^{*}$ Chi-square value, $\mathrm{p}<.05$ is statistically significant

\section{Discussion}

A cross-sectional KAP study was carried out towards cervical cancer, its screening and vaccination among 507 young female medical, dental and pharmacy students with a median age of 22(4) of a private University in Malaysia. The study recorded an overall response rate of $72 \%$ with similar responses reported in Cambodia $(77 \%)$ and $86 \%$ in Nigerian studies.$^{13}$

The results reported in this study are in accordance with Original Bloom's cut-off points, whereas, some studies use Modified Bloom's cut-off points, $75 \%-100 \%, 50 \%-74 \%$, and $<50 \%$ as good, moderate 
and poor respectively. ${ }^{12,14}$ These grading differences could potentially misguide the percentages of reported study's outcome.

\section{Socio-demographic characteristics}

In this study, $75 \%$ of the respondents were aged $21-23$ years; $82 \%$ single at sexually-active age range; $18 \%$ in relationship and mostly $82 \%$, Chinese. A China based multi-center study reported 15-25 years for sexual debut and multiple partners among 11,852 recruited women aged 15-59 years. ${ }^{15}$ Another Nigerian study among college students reported the mean (SD) age at first sexual intercourse was 19 (4) years. ${ }^{16}$ This trend in young age group creates concern over $\mathrm{CC}$ incidence.

\section{Knowledge and awareness of $\mathrm{CC}$}

A majority of the respondents (97\%) had ever heard of CC; $94 \%$ knew, it only infects females; $57 \%$ aware, $\mathrm{CC}$ is symptomless in early stages; $62 \%$ knew, CC symptoms; $83 \%$ believed, it is curable if detected early; $72 \%$ knew, it is detected by Pap test; $80 \%$ knew, it is caused by HPV infection; $57 \%$ knew, the HPV types causing CC; $91 \%$ knew, risk is reduced through vaccination and $72 \%$ were aware, vaccination is available. The high percentage (97\%) of CC awareness may be attributed to the healthcare related background. The results are consistent with reports published from Ghana (93\%); ${ }^{17}$ Republic of Congo (82\%); Ethiopia (79\%); ${ }^{18}$ Korea $(68 \%) .{ }^{19}$ and is contrary to studies reported from South African, Ibadan $<50 \%$ and Nigeria $(71 \% \& 48 \%))^{20-22}$ The main source of information about $\mathrm{CC}$ in this study was mass-media apart from the curriculum content during the pre-clinical and clinical year of their study curriculum and early in the graduation studies from year 2 when introduced to microbiology and pathophysiology courses. Moreover, the national vaccination coverage and the Ministry of health awareness campaign for HPV vaccination and cervical cancer screening through social medias like newspaper, TV and internet play an important role to easily reach a wide community in educating women regarding $\mathrm{CC}$ without any additional cost. Contrary to this, a Kenya study reported, health care providers as the main source of information. ${ }^{23} \mathrm{HPV}$ was the major risk factor reported for $\mathrm{CC}$, followed by multiple sex partners, contraceptive pills, early sexual initiation and smoking. ${ }^{21}$ More than half of the respondents (55\%), 281/507 showed overall poor knowledge regarding risk factors which contravenes the Nigerian studies reporting high awareness among female health professional students. ${ }^{20}$ However, comparatively less awareness prevailed over certain knowledge domains like rate of cc growth (16\%), weather curable? $(17 \%)$, common among women $<30$ years $(34 \%)$ and smoking as a risk factor (43\%). ${ }^{22}$ In Malaysia, the lack of resources, awareness and infrastructure led to low rates of screening in rural areas and hence the increase..$^{23}$ Only about $6 \%$ of Malaysian women are screened for HPV says an estimate. Misperceptions and cultural inhibitions regarding screening procedure and the disease by itself have contributed to low Pap screening. ${ }^{24}$

\section{Attitude and perception towards CC}

The study showed an overall neutral attitude \& perception (338/507), with a highest median score by dental students of 40 (4)/ 50 . Only $27 \%$ showed any positive attitude \& perception towards CC and related domains. Thus, we can infer that most of the students have optimum attitude \& perception towards CC in contrast to positive attitude reported by an Indian study. ${ }^{25} \mathrm{As}$ far as attitude was concerned, a large majority of females (82\%) in this study agreed to participate in screening programs and $79 \%$ knew, Pap test helps early detection. Surprisingly, an overwhelming majority (98\%) from Ghana had never heard about Pap test. ${ }^{25}$ However, fewer females (63\%) were willing to pay for the test. This outcome was comparable with few studies and contradicted with others. ${ }^{22,26}$

This study was conducted eight years after the national HPV vaccination programme was initiated at secondary school levels in Malaysia. Hence, uptake of vaccination reported was high (79\%) and majority $(65 \%)$ had good awareness towards $\mathrm{CC}$ vaccination. ${ }^{27}$ They were also aware of the disease and presence of vaccination for CC. There was more acceptance of HPV vaccination among study participants, when compared among other University students in Malaysia. ${ }^{28}$ The reason could the frequent awareness and vaccination campaigns, repeated KAP surveys on HPV conducted in the university campus. Nevertheless, no significant association were found in intention for HPV vaccine among those dating, married or otherwise. This could possibly be due to bias in reporting regarding relationships in this culturally conservative society. The $72 \%$, total KAP score towards CC $(364 / 506)$ was found to be moderate. However, there was a high prevalence of insufficient knowledge $(55 \%)$ in this study population. Despite low level of knowledge, the attitude \& perception level were fairly optimum $(67 \%)$. The author found that, even though female students had suboptimal levels of knowledge, their attitudes were favourable.

The association between the total knowledge score (TKS) towards $\mathrm{CC}$ and the course of study revealed, the medical students had a better median score 11(3) due to their education curriculum with more clinical information compared to dental and pharmacy education. This phenomenon, proved to be consistent with a study conducted among medical and pharmacy students from two universities in Kuala Lumpur, Malaysia. ${ }^{29}$ The highest positive attitude \& perception (30\%) score was reported among medical students which may be due to more clinical attachments at hospital compared to others courses. However, the total KAP score comparison regarding $\mathrm{CC}$ revealed better KAP scores among pharmacy students (15\%) good. This study failed to find significant association between the TKS or TKAPS and the courses of study. However, there was a significant association between the TAPS and course of study.

\section{Conclusion}

In conclusion, the results presented in this study give an insight into the knowledge, attitude \& perception (KAP) of female university students towards cervical cancer. Although this study revealed that more than half of the students with poor knowledge, most of them have optimum attitude \& perception towards cervical cancer. Therefore, providing clear, precise and required information about the implications of cervical cancer infection, its prevention through early screening and vaccination is of importance. Greater efforts in health education are needed to acquire low cervical cancer incidence and related deaths.

\section{Study limitation}

In spite of taking adequate care to follow the scientifically valid methods of representative samples, selection bias cannot be ruled out entirely as only a small proportion of the total target population was studied and all conclusions are limited to the one university students. 
The study participants may not have been truthful all the time in their responses in apprehension of hurting the sentiments of the interviewers. This study was not able to assess the eligible population inside or outside the university campus of different educational background.

\section{Acknowledgements}

We acknowledge the management of AIMST University, Malaysia for granting permission to conduct this study across the faculties. We are also thankful to the participants, without whose cooperation this study would have been impossible.

\section{Disclosure}

The authors declare no conflicts of interest in this work.

\section{References}

1. Anderson $\mathrm{KC}$, Alsina $\mathrm{M}$, Bensinger $\mathrm{W}$, et al. NCCN clinical practice guidelines in oncology: multiple myeloma. $J$ Natl Compr Canc Netw: 2009;7(9):908-942.

2. Ferlay J, Soerjomataram I, Dikshit R, et al. Cancer incidence and mortality worldwide: sources, methods and major patterns in GLOBOCAN 2012. Int J Cancer. 2015;136(5):E359-386.

3. Anile M, Mantovani S, Pecoraro Y, et al. Pulmonary metastasectomy in uterine malignancies: outcome and prognostic factors. Journal of Thoracic Disease. 2017;9(Suppl 12):S1273-S1277.

4. Beavis AL, Gravitt PE, Rositch AF. Hysterectomy $\square$ corrected cervical cancer mortality rates reveal a larger racial disparity in the United States. Cancer. 2017;123(6):1044-1050.

5. Gunderson LL. Clinical radiation oncology. Elsevier Health Sciences; 2015

6. Datta NR, Samiei M, Bodis S. Radiation therapy infrastructure and human resources in low-and middle-income countries: present status and projections for 2020. Int J Radiat Oncol Biol Phys. 2014;89(3):448457.

7. Hopkins TG, Wood N. Female human papillomavirus (HPV) vaccination: global uptake and the impact of attitudes. Vaccine. 2013;31(13):1673-1679.

8. Malaysia: Human Papillomavirus and Related Cancers. 2017.

9. Terefe Y, Gaym A. Knowledge, attitude and practice of screening for carcinoma of the cervix among reproductive health clients at three teaching hospitals, Addis Ababa, Ethiopia. Ethiop J reprod Health. 2008;2(1).

10. S de Sanjose, Temin S, Garland S, et al. Primary Prevention of Cervical Cancer: American Society of Clinical Oncology Resource-Stratified Guideline Summary. J Oncol Pract. 2017;13(7):452-457.

11. Jaglarz K, Tomaszewski KA, Kamzol W, et al. Creating and field-testing the questionnaire for the assessment of knowledge about cervical cancer and its prevention among schoolgirls and female students. $J$ Gynecol Oncol. 2014;25(2):81-89.

12. Kaliyaperumal KI. Guideline for conducting a knowledge, attitude and practice (KAP) study. AECS illumination. 2004;4(1):7-9.

13. Bansal AB, Pakhare AP, Kapoor N, et al. Knowledge, attitude, and practices related to cervical cancer among adult women: A hospital- based cross-sectional study. J Nat Sci Biol Med. 2015;6(2):324-328.

14. Tarahomi M, Yaghmaie F, Asadi S, et al. Preventing mother-to-child transmission of HIV/AIDS: do Iranian pregnant mothers know about it? J Reprod Infertil. 2010;11(1):53

15. Zhao FH, Tiggelaar SM, Hu SY, et al. A multi-center survey of age of sexual debut and sexual behavior in Chinese women: suggestions for optimal age of human papillomavirus vaccination in China. Cancer Epidemiol. 2012; 36(4):384-390.

16. Eniojukan Joshua F, Ganiyu Kehinde A, Ikoah Celestine N. Cervical cancer knowledge, awareness, screening and vaccination among female undergraduate heath professional students of Niger Delta University in south-south Nigeria. WJPR. 2015;4(11):2100-2114.

17. Leung JT, Law CK. Revisiting knowledge, attitudes and practice (KAP) on human papillomavirus (HPV) vaccination among female university students in Hong Kong. Hum Vaccin Immunother. 2018;14(4):924-930.

18. Touch S, Oh JK. Knowledge, attitudes, and practices toward cervical cancer prevention among women in Kampong Speu Province, Cambodia. BMC cancer. 2018;18(1):294

19. Tran NT, Choe SI, Taylor R, et al. Knowledge, attitude and practice (KAP) concerning cervical cancer and screening among rural and urban women in six provinces of the Democratic People's Republic of Korea. Asian Pac J Cancer Prev. 2011;12(11):3029-3033.

20. Hoque E, Hoque M. Knowledge of and attitude towards cervical cancer among female university students in South Africa. South Afr J Epidemiol Infect. 2009;24(1):21-24.

21. Ahmed SA, Sabitu K, Idris SH. Knowledge, attitude and practice of cervical cancer screening among market women in Zaria, Nigeria. Niger Med J. 2013;54(5):316-319.

22. Nwozor CM, Oragudosi AL. Awareness and uptake of cervical cancer screening among women in Onitsha, South-East, Nigeria. Greener $J$ Med Sci. 2013;3(8):283-288.

23. Zaridah S. A review of cervical cancer research in Malaysia. Med $J$ Malaysia. 2014;69(Suppl A):33-41.

24. Wong LP, Sam IC. Ethnically diverse female university students' knowledge and attitudes toward human papillomavirus (HPV), HPV vaccination and cervical cancer. Eur J Obstet Gynecol Reprod Biol. 2010;148(1):90-95.

25. Mutyaba T, Mmiro FA, Weiderpass E. Knowledge, attitudes and practices on cervical cancer screening among the medical workers of Mulago Hospital, Uganda. BMC Med Educ. 2006;6(1):13.

26. Aswathy S, Quereshi MA, Kurian B. Cervical cancer screening: Current knowledge \& practice among women in a rural population of Kerala, India. Indian J Med Res. 2012;136(2):205-510.

27. Ebu NI, Mupepi SC, Siakwa MP, Sampselle CM. Knowledge, practice, and barriers toward cervical cancer screening in Elmina, Southern Ghana. Int J Womens Health. 2015;7:31-39.

28. Rashwan HH, Saat NZ, Manan DN. Knowledge, attitude and practice of malaysian medical and pharmacy students towards human papillomavirus vaccination. Asian Pac J Cancer Prev. 2012;13(5):22792283 .

29. Goyal A, Vaishnav G, Shrivastava A, et al. Knowledge, attitude \& practices about cervical cancer and screening among nursing staff in a teaching hospital. Int J Med Sci Public Health. 2013;2(2):249-253. 